\title{
O JOGO DIGITAL COMO PROPOSTA DE GAMIFICAÇÃO NO ENSINO DE HISTÓRIA DA MATEMÁTICA
}

\section{THE DIGITAL GAME AS PROPOSAL OF GAMIFICATION IN TEACHING THE HISTORY OF MATHEMATICS}

\author{
Thomas Bersagui Milano ${ }^{1}$ \\ Faculdade Inedi - Cesuca \\ Mirian Linhares Siqueira ${ }^{2}$ \\ Faculdade Inedi - Cesuca \\ Fernanda Chites Azevedo ${ }^{3}$ \\ Faculdade Inedi - Cesuca \\ Lucas Nunes Ogliari ${ }^{4}$ \\ Universidade Federal do Rio Grande - FURG
}

\begin{abstract}
Resumo
O tema norteador do presente artigo científico se refere à gamificação no ensino de matemática, tendo como base a problematização "Como a gamificação pode ser inserida no contexto do ensino de história da matemática?", formulada na disciplina de história da matemática do curso de Licenciatura em Matemática da Faculdade Inedi - Cesuca (Complexo de Ensino Superior de Cachoeirinha). Estipulou-se como objetivo da pesquisa descrever o funcionamento de um jogo digital que atue como uma proposta de gamificação no ensino desta disciplina, tendo a finalidade de motivar os acadêmicos e de influenciar no processo de aprendizagem. O método utilizado foi a pesquisa exploratória e bibliográfica, com o intento de perscrutar materiais que aludem a temática para clarificar os conceitos e se familiarizar sobre o assunto. $O$ jogo desenvolvido foi intitulado de "História da Matemática: O Aprendiz", o qual foi ambientado utilizando a plataforma RPG Maker VX Ace Lite, tendo como personagem um estudante que almeja se tornar um aprendiz no estudo da história da matemática. No enredo do jogo os desafios propostos contemplam tópicos relacionados com a ementa da disciplina, portanto este recurso pode ser utilizado para a realização de um feedback abordando sobre os conhecimentos construídos ao longo do semestre, recorrendo às características motivacionais agregadas na utilização da gamificação no ensino, e na utilização de jogos digitais como recurso metodológico. Mediante a revisão de literatura sobre o tema abordado, concluiu-se que recorrer ao jogo digital como uma proposta de gamificação no ensino pode impactar positivamente no aprendizado dos estudantes, visto que as particularidades presentes nos jogos foram referidas como um método motivacional, sustentando a concepção de que a gamificação no contexto educacional deve ser explorada.
\end{abstract}

\footnotetext{
${ }^{1}$ thomas_tbm@hotmail.com

2 myrian.siqueira@hotmail.com

3 fchites@gmail.com

${ }^{4}$ lucasbass@yahoo.com.br
} 
Palavras-chave: Gamificação; jogos digitais; história da matemática.

\begin{abstract}
he guiding theme of the present scientific article refers to the gamification in the teaching of mathematics, based on the problematization "How can gamification be inserted in the context of the teaching of the history of mathematics?" Formulated in the discipline of the history of mathematics of the course of Bachelor in Mathematics from Faculdade Inedi - Cesuca (Complexo de Ensino Superior de Cachoeirinha). It was stipulated as a goal of the research to describe the operation of a digital game that acts as a proposal of gamification in the teaching of this discipline, with the purpose of motivating the students and influencing the learning process. The method used was the exploratory and bibliographical research, with the aim of examining materials that allude to the theme to clarify the concepts and become familiar with the subject. The developed game was titled "History of Mathematics: The Apprentice", which was acclimated using the platform RPG Maker VX Ace Lite, having as character a student who aims to become an apprentice in the study of the history of mathematics. In the plot of the game the proposed challenges contemplate topics related to the discipline's syllabus, so this resource can be used to provide feedback about the knowledge constructed during the semester, using the aggregate motivational characteristics in the use of gamification in teaching, and the use of digital games as a methodological resource. By reviewing the literature on the subject, it was concluded that recourse to the digital game as a proposal of gamification in teaching can positively impact student learning, since the particularities present in the games were referred to as a motivational method, supporting the conception that the gamification in the educational context should be explored.
\end{abstract}

Keywords: Gamification; Digital games; history of mathematics.

\title{
Introdução
}

A pesquisa desenvolvida no presente artigo tematizou os jogos digitais como uma proposta de gamificação no ensino de história da matemática, delimitando-se a descrever o funcionamento de um jogo digital que pode ser aplicado com acadêmicos do curso de Licenciatura em Matemática. A inclinação por este assunto se deu pelo intento de proporcionar uma motivação extra para os discentes que cursarem a disciplina de história da matemática, buscando aporte nas características que sustentam a implementação da gamificação no ensino e os atributos que os jogos digitais podem apresentar.

A conceituação de gamificação, segundo Paula (2016), não se define apenas na utilização de jogos, mas se refere ao uso dos elementos presentes nos jogos, como por exemplo, as estratégias, para alcançar um objetivo que não seja apenas o entretenimento, ou seja, a gamificação não deve ser confundida com um jogo ou com o ato de jogar. A intenção desta tendência é recorrer às particularidades presentes neste 
recurso para atingir propósitos específicos, podendo contribuir para o estímulo da motivação e da aprendizagem. Recorrendo ao jogo digital como uma estratégia voltada ao ensino utilizamos a tecnologia a favor da Educação, demonstrando que é possível que ambas se articulem de modo que contribuam para a construção do conhecimento, além de propiciar um ambiente recreativo e agradável, que seja suscetível ao aprendizado. Posto isto, é importante salientar que a intenção aqui manifestada é utilizar os jogos digitais como uma proposta de gamificação no ensino, onde os elementos de jogos são inseridos no âmbito da sala de aula.

O questionamento "Como a gamificação pode ser inserida no contexto do ensino de história da matemática?", motivou a problematização que norteou a pesquisa desenvolvida neste estudo, uma vez que, por meio desta indagação, visou-se investigar o uso da gamificação no âmbito educacional. Diante de tal questão, configurou-se como objetivo geral descrever o funcionamento de um jogo digital voltado para o ensino desta unidade de aprendizagem, abrangendo características da gamificação. Ademais, por objetivo específico se estabeleceu realizar pesquisas bibliográficas, com caráter exploratório, perscrutando materiais acerca do tema gamificação e jogos digitais, a fim de sustentar a aplicação da proposta elaborada.

Os jogos digitais e a gamificação dispõem de atributos que podem ser utilizados para motivar os estudantes a se envolver em atividades específicas, viabilizando um entretenimento estimulador que pode beneficiar o processo de aprendizagem. Neste cenário, o jogo desenvolvido, intitulado de "História da Matemática: O Aprendiz", tem por destinação atuar como uma ferramenta motivadora, retomando os conteúdos presentes no ensino da disciplina de história da matemática na graduação.

O artigo está organizado em cinco seções. Após a introdução, na segunda seção é abordada a literatura acerca do tema gamificação e jogos digitais no ensino, com o intuito de fundamentar o artigo. A terceira seção se refere ao método adotado, o qual consiste em uma pesquisa exploratória e bibliográfica com a finalidade de proporcionar uma interação sobre a temática abordada. O jogo digital "História da Matemática: $\mathrm{O}$ Aprendiz" é descrito na quarta seção, relatando o enredo e os objetivos presentes na proposta. Concluindo, na última seção são apresentadas as considerações finais a respeito do desenvolvimento da pesquisa.

\section{Gamificação e jogos digitais no ensino}


A nossa sociedade está presenciando uma era de inovação tecnológica, onde a tecnologia ganha cada vez mais espaço em diversos contextos; neste cenário, propostas de jogos digitais e de gamificação podem atuar como articuladores entre estas áreas. Segundo Vianna et al. (2013, p. 13), a "gamificação (do original em inglês gamification) corresponde ao uso de mecanismos de jogos orientados ao objetivo de resolver problemas práticos ou de despertar engajamento entre um público específico”. Para Busarello, Ulbricht e Fadel (2014, p. 15) a "Gamificação tem como base a ação de se pensar como em um jogo, utilizando as sistemáticas e mecânicas do ato de jogar em um contexto fora de jogo". Recorrer a gamificação compreende inserir elementos característicos dos jogos em ambientes que não são nativos dos jogos, como por exemplos, em escolas e empresas.

No que tange a educação, a intenção da gamificação é utilizar as características dos jogos, bem como as suas contribuições, para despertar interesse e motivar os estudantes, recorrendo a ludicidade presente nesta proposta, sendo, conforme Vianna et al. (2013, p. 108) "a educação uma das áreas em que se tem maior expectativa com relação à extensão de benefícios passíveis de serem alcançados com a gamificação". Ao considerar a gamificação como uma tendência metodológica, parte-se do pressuposto que ela refletirá positivamente na aprendizagem, uma vez que ela viabiliza ambientes que podem apresentar caráter motivacional, impactando no cenário da Educação.

A gamificação é entendida por Garcia (2015) como uma nova tendência metodológica, a qual visa à motivação na aprendizagem e, segundo Alves e Teixeira (2014, p. 124), neste contexto os "objetos gamificados atuariam como objetos de aprendizagem estruturados como jogos ou que adotam algumas características destes". Neste âmbito, uma aula, uma gincana ou um projeto, podem ser contextualizados como objetos gamificados, desde que apresentem características pertinentes aos jogos, como por exemplo, sistemas de recompensa, níveis hierárquicos, regras, competição, feedback, etc.

Vianna et al. (2013) consideram que para ativar a criatividade das pessoas é muito importante que ela sinta prazer em executar uma determinada atividade, pois assim ela se dedicaria ao que foi proposto, gerando uma emoção positiva, sendo a motivação um fator essencial para que o sujeito desempenhe uma demanda específica. Alves e Teixeira (2014, p. 140) ponderam que a "gamificação pode explorar qualidades 
cognitivas, sociais, culturais e motivacionais", o que reflete positivamente no desempenho e na aprendizagem de cada sujeito que participa desta proposta.

\begin{abstract}
O foco da gamificação é envolver emocionalmente o indivíduo dentro de uma gama de tarefas realizadas. Para isso se utiliza de mecanismos provenientes de jogos que são percebidos pelos sujeitos como elementos prazerosos e desafiadores, favorecendo a criação de um ambiente propício ao engajamento do indivíduo. Esse engajamento, por sua vez, pode ser medido e visto como os níveis de relação entre sujeito e o ambiente - trabalho e outras pessoas -, e é um dos principais fatores a serem explorados dentro dos recursos de gamificação. Isso porque é o foco da própria gamificação e responsável pelo sucesso ou insucesso do jogo enquanto estratégia. Compreende-se que a criação de ambientes que interajam positivamente com as emoções dos indivíduos favoreça o crescimento desses níveis de engajamento. (BUSARELLO; ULBRICHT; FADEL, 2014, p. 33 - 34)
\end{abstract}

Pode ser comum que as pessoas tenham resistência a fazer algo que não tenham motivação, tanto no ambiente escolar quanto no laboral, logo, para que haja um maior interesse e envolvimento por parte destes sujeitos, Alves e Teixeira (2014) entendem que a gamificação pode ser utilizada como uma estratégia de aprendizagem e interação social, que envolve a ludicidade e elementos motivacionais relacionados aos jogos.

Rosetti Jr et al. (2015) apontam que as pessoas estão cada vez mais conectadas nos ambientes das redes sociais e dos jogos e, posto isso, as escolas não podem agir de maneira excludente em relação a esta situação, uma vez que esses fatores devem ser levados em consideração, de modo que as práticas sejam repensadas, integrando a realidade na sala de aula com a finalidade de despertar interesse e motivar. Neste âmbito, Alves, Minho e Diniz (2014, p. 83) sustentam que a gamificação pode ser "uma possibilidade de conectar a escola ao universo dos jovens com o foco na aprendizagem", concentrando-se em "promover experiências que envolvem emocionalmente e cognitivamente os alunos" (ALVES; MINHO; DINIZ, 2014, p, 83).

Quando no contexto educacional, jogos digitais podem ser inseridos nas propostas de gamificação, devendo apresentar características pedagógicas, ou seja, devem dispor de um caráter educativo, com finalidades voltadas ao aprendizado. Para Lima e Moita (2011, p. 131) o jogo digital pode ser uma ferramenta didática, sendo considerado "um recurso tecnológico lúdico, que agrega fatores como: diversão, prazer, habilidades e conhecimentos", o que pode contribuir, deste modo, para que haja um engajamento por parte dos estudantes para se realizar uma atividade ou estudo específico. 
Para se configurar como um jogo, de acordo com McGonigal (2012, apud VIANNA et al., 2013, p. 28), quatro características devem se fazer presentes, quais sejam: "meta, regras, sistema de feedback e participação voluntária". As metas são os motivos que levam alguém a realizar determinada atividade e as regras são as condicionantes para a execução. Busarello, Ulbricht e Fadel (2014, p. 23) acreditam que o "jogador deve aceitar as regras estabelecidas pelo jogo para atingir alguma meta por meio da superação de uma série de obstáculos". Conforme Vianna et al. (2013), a característica relacionada com o feedeback diz respeito a informar os jogadores sobre o seu progresso na atividade e motivá-los a prosseguir; já a participação voluntária se refere ao fato de que os jogadores devem participar por vontade própria, aceitando o jogo como ele foi proposto.

Os jogos, digitais ou não, quando inseridos em um contexto, como, por exemplo, o educacional, podem proporcionar recompensas aos jogadores, as quais, de acordo com Vianna et al. (2013, p. 35), "representam a principal razão pela qual os jogadores se motivam a persistir em um jogo até sua conclusão, ou mesmo permanecerem jogando, nos casos em que a proposta não contempla o conceito de finitude". Entretanto, a oferta de recompensas não são características obrigatórias dos jogos, podendo ser acrescidas conforme as intenções do idealizador da proposta, pois quando o jogo é voltado para fins didáticos a principal recompensa que se deve pretender adquirir é o conhecimento.

Segundo Savi e Ulbricht (2008, n.p.), os jogos digitais educacionais podem contribuir significativamente no ensino e na aprendizagem ativa, pois são práticas atrativas e inovadoras que motivam os alunos. Em meio a tantas tecnologias que podem direcionar o foco dos estudantes para assuntos que não estão relacionados ao aprendizado, faz-se necessário que as estratégias utilizadas em aula sejam dinâmicas e prazerosas, para despertar o interesse pelo conhecimento e se desvencilhar das aulas que por vezes são maçantes e cansativas.

Dentre as nomenclaturas que podem ser utilizadas para distinguir os jogos digitais educacionais, Savi e Ulbricht (2008, n.p.) sugerem como sendo as mais comuns “jogos educacionais ou educativos, jogos de aprendizagem ou jogos sérios (serious games), sendo que alguns tipos de simuladores também podem ser considerados jogos educacionais". 
Em se tratando da utilização de jogos digitais no ensino superior, Silva et al. (2017) constataram, por meio de revisões sistemáticas da literatura internacional, que dentre as justificativas para a utilização deste recurso estão o aprimoramento de habilidades, exploração de conhecimentos e motivação mediante a tarefas ativas. As considerações apontadas pelos autores elucidam a potencialidade dos jogos digitais como um recurso metodológico, visto que remetem a possibilidade de se atingir resultados positivos na aprendizagem e no processo de construção do conhecimento.

\section{Caminho metodológico}

O método empregado no presente artigo se caracteriza como uma pesquisa exploratória, onde a finalidade é se inteirar sobre a temática da gamificação e dos jogos digitais como uma proposta de ferramenta a ser utilizada nos ambientes de aprendizagem. Para Cervo, Bervian e Da Silva (2007, p. 63), este tipo de pesquisa tem como "objetivo familiarizar-se com o fenômeno ou obter uma nova percepção dele e descobrir novas ideias".

Para idealizar a proposta de um jogo digital que envolve conhecimentos acerca da história da matemática, com vistas à aplicação em um curso de ensino superior, fezse necessário primeiramente perfazer uma sondagem sobre o tema gamificação e jogos digitais, com a intenção de elucidar os conceitos que permeiam o assunto. Tal intenção se enquadra com as finalidades da pesquisa exploratória, as quais são, segundo Marconi e Lakatos (2010, p. 171), “desenvolver hipóteses, aumentar a familiaridade do pesquisador com um ambiente, fato ou fenômeno, para a realização de uma pesquisa futura mais precisa, ou modificar e clarificar conceitos”.

Como a pesquisa possui caráter exploratório, configura-se também como pesquisa bibliográfica, uma vez que materiais bibliográficos foram revisados a fim de embasar o referencial teórico. Este tipo de pesquisa, de acordo com Marconi e Lakatos (2010, p. 166), tem por objetivo "colocar o pesquisador em contato direto com tudo o que foi escrito, dito ou filmado sobre determinado assunto".

\section{Descrição do jogo digital "História da Matemática: O Aprendiz"}

A intenção do jogo digital descrito nesta seção tem caráter motivador, sendo estruturado com base em tópicos presentes na ementa da disciplina de história da matemática, do curso de Licenciatura em Matemática da Faculdade Inedi - Cesuca 
(Complexo de Ensino Superior de Cachoeirinha). A ideia foi elaborada com a finalidade de ser aplicada após o desenvolvimento dos conteúdos presentes no cronograma, atuando como recurso para realização de um feedback abordando sobre os conhecimentos construídos ao longo do semestre. Ademais, pode-se agregar a esta proposta a competição entre os jogadores e sistemas de recompensa, de modo que se fortifique a caracterização como um objeto gamificado.

O jogo "História da Matemática: O Aprendiz", desenvolvido pelos autores deste artigo, foi criado utilizando a plataforma RPG Maker VX Ace Lite e se passa em cidades fictícias, na perspectiva de terceira pessoa, tendo como personagem um estudante chamado Tommy. Ao acessar o jogo, conforme a figura 1, a tela inicial conta com as opções "Iniciar", "Continuar" e "Sair". A opção "Continuar" pode ser utilizada quando os jogadores salvarem o progresso através do menu do jogo.

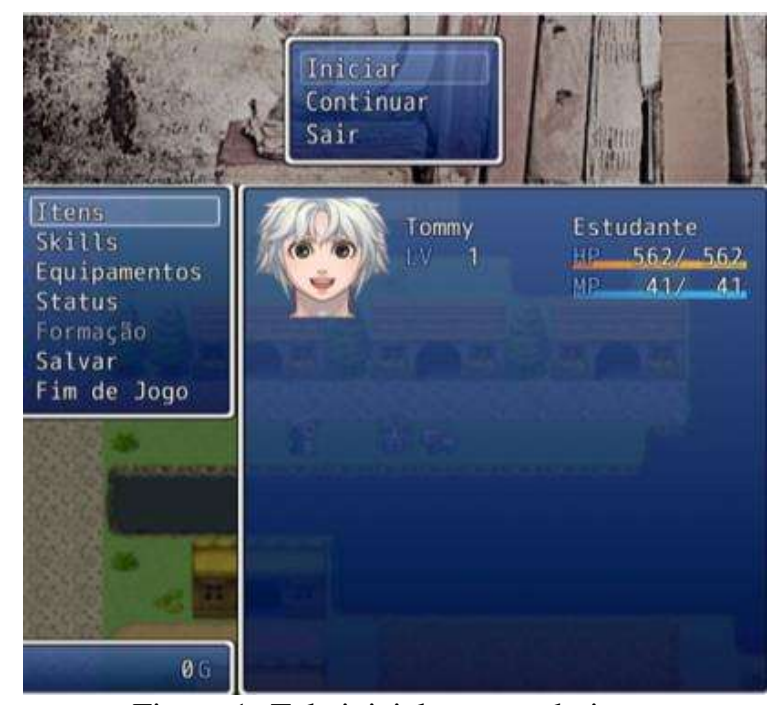

Figura 1- Tela inicial e menu do jogo.

Fonte: Os autores.

$\mathrm{Na}$ figura 2 estão apresentados alguns dos cenários que ambientam o jogo. Estes ambientes compreendem os locais que o jogador irá explorar no decorrer da jornada, como por exemplo, cidades e residências para as quais o personagem será encaminhado, onde irá interagir com os NPCs (personagens não jogáveis). 


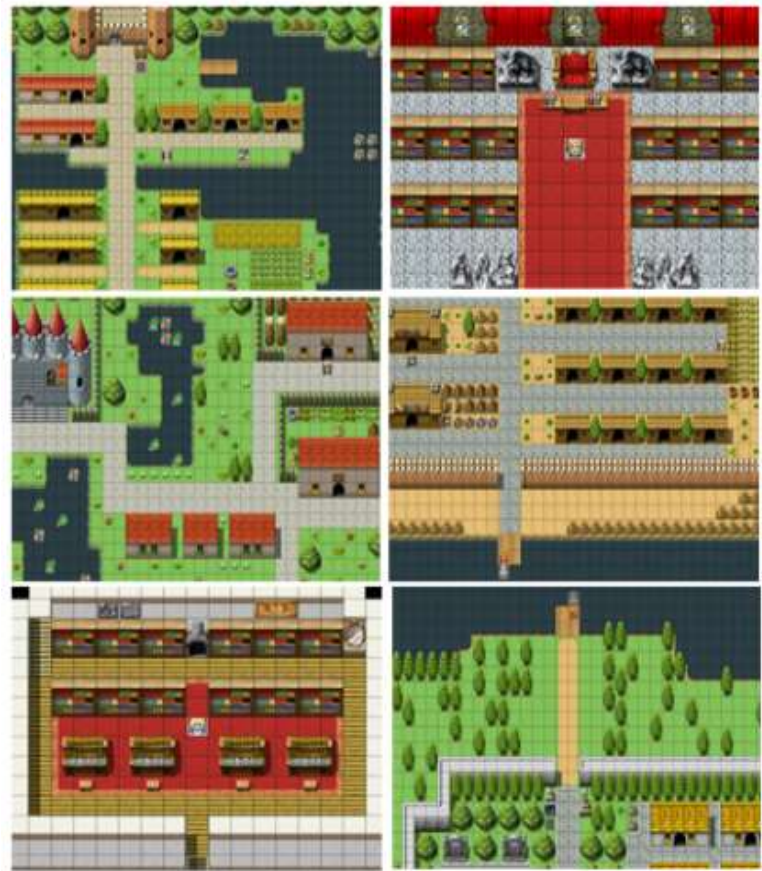

Figura 2 - Cenários do jogo. Fonte: Os autores.

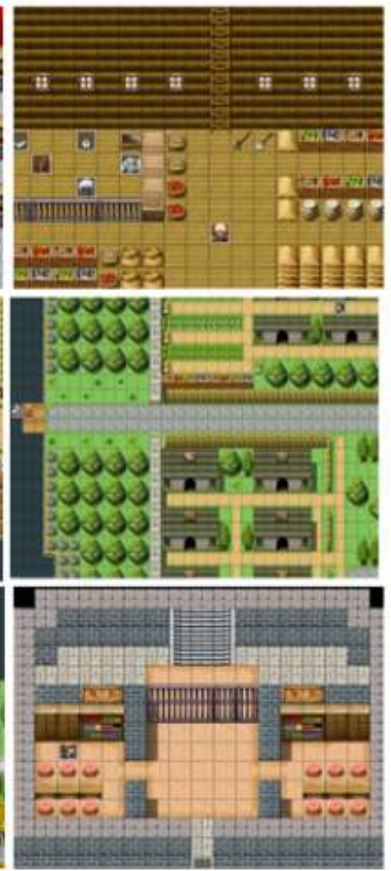
$=$

Antes de a jornada iniciar, o jogador é apresentado à história do jogo, por meio da seguinte mensagem: "Seu nome é Tommy, você é um estudante de matemática que tem o sonho de se tornar um mestre da História da Matemática, para tanto, você se preparou durante muito tempo, estudando aplicadamente. Hoje é o dia para qual você tanto se dedicou, o dia do teste para se tornar Aprendiz do Grande Mestre do Castelo dos Sábios. Para finalmente se tornar Aprendiz você terá que responder cinco questões, das quais não poderá errar nenhuma. Chegou a hora, boa sorte!”.

O objetivo inicial do personagem é realizar um teste para poder se tornar aprendiz sobre a história da matemática, sendo encaminhado posteriormente para o início do seu treinamento. O jogo foi dividido em cinco etapas, onde cada uma se configura por uma ou mais atividades relacionadas aos tópicos presente na ementa da disciplina de história da matemática. A primeira etapa compreende o teste, com cinco perguntas, para se tornar o aprendiz do Grande Mestre do Castelo dos Sábios - o Grande Mestre é o NPC que mais interage com o jogador, uma vez que ele é o responsável pela demanda das atividades que devem ser realizadas -; as questões envolvem os primeiros indícios históricos da matemática, os números digitais, o ábaco, a tábula Plimpton 322 e o papiro Rhind, sendo que as respostas, tanto nesta quanto nas demais etapas, são apresentadas com a condição de verdadeiro ou falso ou com opções de múltipla escolha. Esta primeira parte é a única onde o jogador não pode errar 
nenhuma pergunta, pois caso isso aconteça aparecerá a mensagem de Game Over (fim de jogo) e, consequentemente, será necessário iniciar o jogo novamente. A partir da etapa dois, quando o jogador errar uma resposta do desafio ele será informado sobre qual era a alternativa correta e sempre que ele acertar receberá um código fornecido pelo NPC Grande Mestre, como no exemplo da figura 3; a intenção é que estes códigos sejam utilizados como um recurso para promover um feedback ao término do jogo, permitindo que o professor acompanhe como foi o desempenho de cada acadêmico na resolução das atividades.

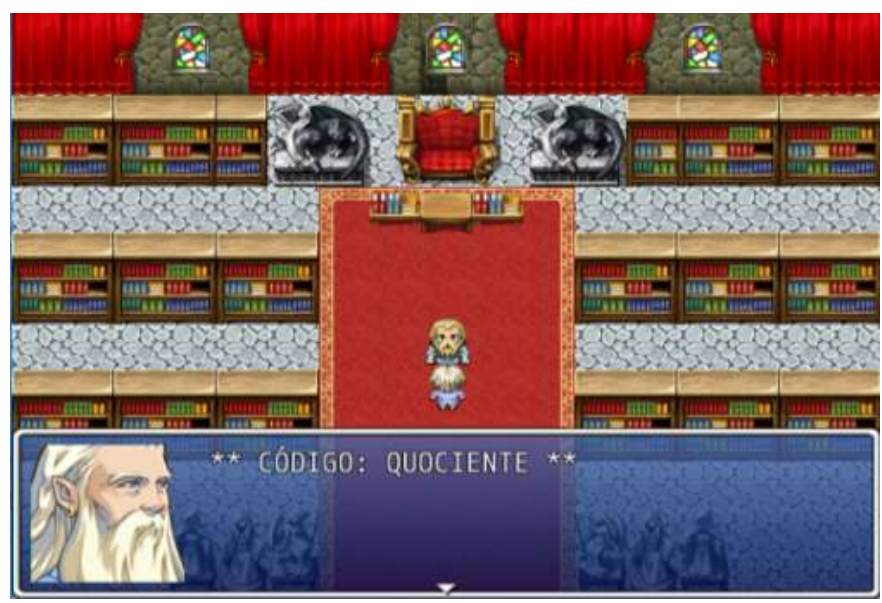

Figura 3 - Exemplo de código referente ao acerto de questões. Fonte: Os autores.

A segunda etapa ocorre após a aprovação do teste, onde o personagem inicia o seu treinamento como aprendiz. Sua primeira tarefa é ajudar o NPC Sr. Germano (figura 4), que reside nas fazendas do vilarejo, a descobrir qual o comprimento deve ter uma rampa que ele gostaria de construir em seu celeiro, utilizando os conhecimentos sobre o Teorema de Pitágoras para resolução da atividade. Já a terceira etapa envolve conhecimentos relacionados a Tales de Mileto e Euclides de Alexandria, compreendendo especificamente o Teorema de Tales e o algoritmo do MDC (Máximo Divisor Comum), com a intenção de ajudar a NPC Sra. Lanna (figura 4), na marcenaria da capital, a resolver problemas com relação às medidas para a construção de uma pequena estante e de uma ponte para ligar vilarejos. A quarta etapa ocorre logo quando o jogador completa a missão anterior, onde o $N P C$ Grande Mestre realiza quatro perguntas abrangendo a escrita do povo mesopotâmio, as frações egípcias no "Olho de Hórus", o método do retorno utilizado pelos hindus e o Código de César empregado na criptografia. 


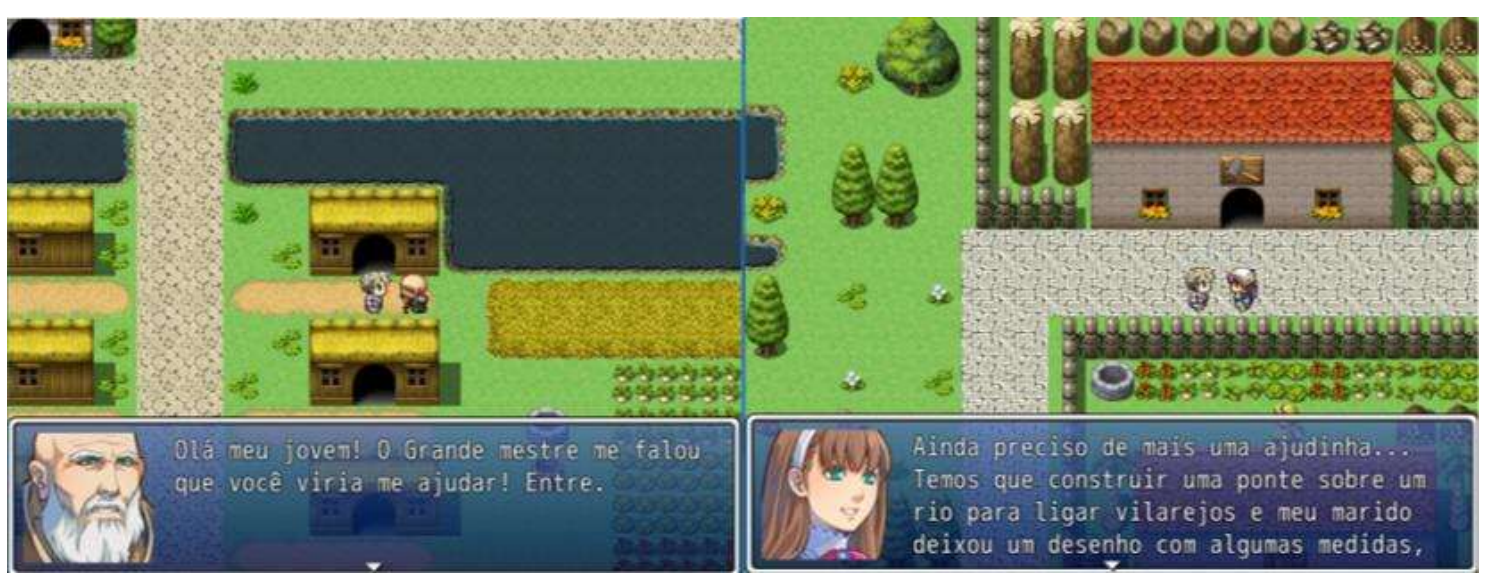

Figura 4 - NPCs Sr. Germano e Sra. Lanna

Fonte: Os autores.

Para finalizar a jornada, a última etapa compreende um teste sobre reconhecimento de matemáticos importantes, por meio de fatos presentes nas suas biografias e pelas suas contribuições, onde o jogador viaja para três cidades com a missão de descobrir qual matemático cada uma representa, para tanto deverá conversar com os NPCs presentes nos cenários, os quais fornecerão informações para que o jogador possa reconhecer os matemáticos. Na tabela 1 estão especificados os três matemáticos e os tópicos que envolvem as dicas oferecidas sobre eles.

Tabela 1: Matemáticos da quinta etapa do jogo.

\begin{tabular}{|c|c|c|}
\hline & Matemático & Tópicos sobre as Dicas \\
\hline Cidade 1 & $\begin{array}{l}\text { Arquimedes de Siracusa } \\
\text { (Antiguidade) }\end{array}$ & $\begin{array}{l}\text { Parafuso de Arquimedes; Alavancas e Catapultas; } \\
\text { Espelhos de Arquimedes; Método de Exaustão; } \\
\text { Fraude na Coroa do Rei; Planetário Hidráulico. }\end{array}$ \\
\hline Cidade 2 & $\begin{array}{l}\text { Leonardo Fibonacci } \\
\text { (Idade Média) }\end{array}$ & $\begin{array}{l}\text { Problema dos Coelhos; Sequência de Fibonacci; } \\
\text { Números de Fibonacci nas Flores; Algarismos } \\
\text { Arábicos, Livro "Liber Abaci"; Números de } \\
\text { Fibonacci na Música. }\end{array}$ \\
\hline Cidade 3 & $\begin{array}{l}\text { René Descartes } \\
\text { (Idade Moderna) }\end{array}$ & $\begin{array}{l}\text { Frase "Penso, logo existo"; Ovais } \\
\text { Operações Elementares utilizando Régua e } \\
\text { Compasso; Regra de Sinais das Raízes Positivas de } \\
\text { um Polinômio; Origem do Plano Cartesiano; } \\
\text { Cartografia; Geometria Analítica. }\end{array}$ \\
\hline
\end{tabular}

Fonte: Os autores.

A interação para avançar de uma cidade a outra é realizada por meio da $N P C$ Ellaria (figura 5), responsável por conduzir o jogador até cada mapa e por trazê-lo de volta ao Castelo dos Sábios. 


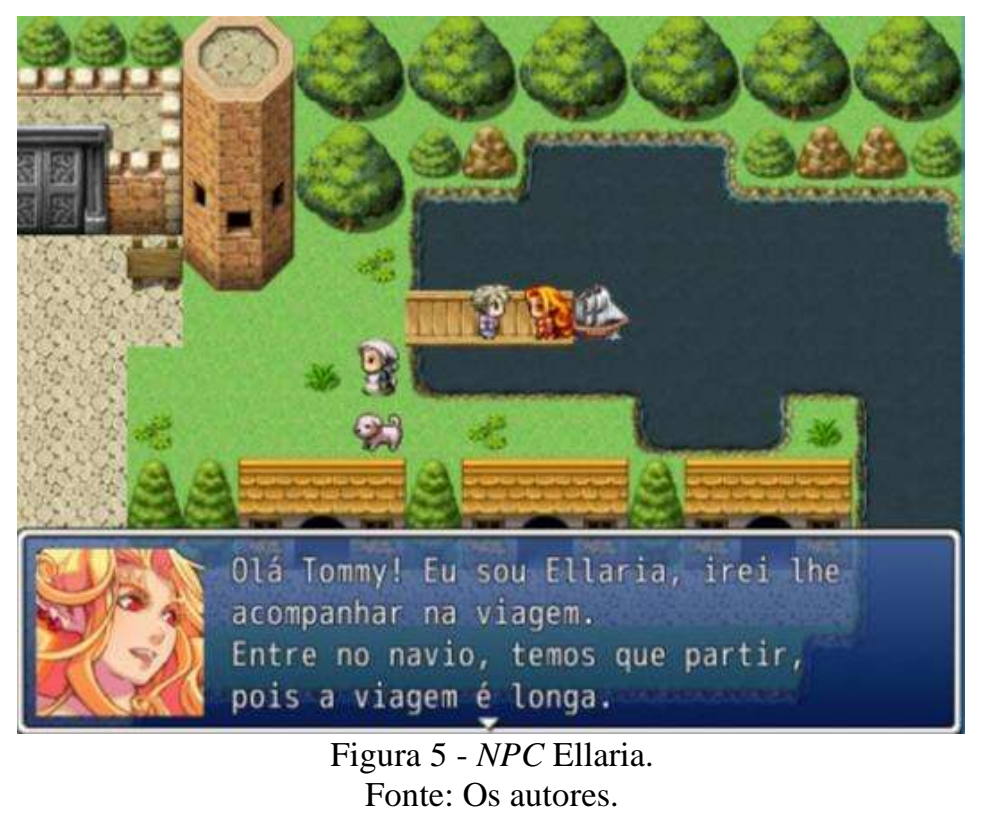

Para finalizar a quinta etapa o jogador voltará ao Castelo dos Sábios a fim de relatar a sua atividade, devendo informar ao NPC Grande Mestre quais foram as suas conclusões neste teste, respondendo qual matemático que cada cidade representava. Após a execução do teste, o jogo é concluído e o jogador é parabenizado pelo seu desempenho durante o treinamento, conforme a seguinte mensagem: "Bom meu aprendiz, durante o seu treinamento notei que você aprendeu bastante e tem muito potencial, parabéns! Eu terei que ir viajar para resolver alguns assuntos em outra cidade e você ficará aqui no Castelo dos Sábios, ajudando as pessoas enquanto eu estiver fora. Aproveite e estude muito sobre a História da Matemática, existem coisas incríveis sobre este assunto. Partirei amanhã, boa sorte! ** FIM DE JOGO - PARABÉNS! **”. Posteriormente a mensagem, o jogador é redirecionado para a tela inicial do jogo e sua jornada é concluída.

\section{Considerações finais}

O objetivo da pesquisa foi descrever o funcionamento de um jogo digital como proposta de gamificação no ensino de história da matemática, com o intuito de responder a problematização "Como a gamificação pode ser inserida no contexto do ensino de história da matemática?". Para tanto, primeiramente realizou-se uma pesquisa bibliográfica e exploratória em livros e artigos científicos a fim de familiarizar-se com os temas presentes, clarificando os conceitos necessários para sustentar a escolha por tal recurso. A intenção do jogo "História da Matemática: O Aprendiz", desenvolvido na 
plataforma RPG Maker VX Ace Lite, é a aplicação após o desenvolvimento dos conteúdos, de modo que atue como um recurso para realização de um feedback, abordando os conhecimentos construídos. Ademais, pretende-se que o jogo seja capaz de motivar os acadêmicos e auxiliar na aprendizagem.

Por meio da revisão de literatura se constatou que a gamificação no ensino pode ser utilizada para despertar o interesse, desenvolver o cognitivo e motivar os estudantes, pressupondo-a como uma metodologia que pode ser oportuna no estimulo e otimização do processo de ensino e aprendizagem. Os jogos digitais, por sua vez, apresentam um caráter lúdico, capaz de proporcionar prazer na realização das atividades e propiciar um ambiente de entretenimento enquanto se aprende, além de articular a tecnologia com a educação. De tal modo, acreditamos que recorrer ao jogo digital como uma proposta de gamificação no ensino de história da matemática possa impactar positivamente no aprendizado, uma vez que as características presentes nos jogos foram listadas como um recurso motivador, sustentando a concepção de que a gamificação no contexto educacional deve ser explorada.

$\mathrm{O}$ estudo aqui realizado se limitou a relatar o funcionamento do jogo digital em questão, portanto, considera-se pertinente a aplicação do jogo "História da Matemática: O Aprendiz" com alunos da graduação, com a finalidade de coletar dados que subsidiem um relato de experiência que vise analisar na prática as contribuições da gamificação e dos jogos digitais no ensino, verificando a aceitação deste modelo de proposta e averiguando como os discentes procedem neste contexto.

\section{Referências}

ALVES, Lynn Rosalina Gama; MINHO, Marcelle Rosa da Silva; DINIZ, Marcelo Vera Cruz. Gamificação: diálogos com a educação. In: Fadel, Luciane Maria; et al. Gamificação na educação. São Paulo: Pimenta Cultural, 2014.

ALVES, Marcia Maria; TEIXEIRA, Oscar. Gamificação e objetos de aprendizagem: contribuições da gamificação para o design de objetos de aprendizagem. In: Fadel, Luciane Maria; et al. Gamificação na educação. São Paulo: Pimenta Cultural, 2014.

BUSARELLO, Raul Inácio; ULBRICHT, Vania Ribas; FADEL, Luciane Maria. A gamificação e a sistemática de jogo: conceitos sobre a gamificação como recurso motivacional. In: Fadel, Luciane Maria; et al. Gamificação na educação. São Paulo: Pimenta Cultural, 2014. 
Thomas B. Milano, Mirian L. Siqueira, Fernanda C. Azevedo, Lucas N. Ogliari

O jogo digital como proposta de gamificação no ensino de história da matemática

CERVO, Amado Luiz; BERVIAN, Pedro Alcino; DA SILVA, Roberto. Metodologia científica. 6. ed. São Paulo: Pearson Prentice Hall, 2007.

GARCIA, Adriana. Gamificação como prática pedagógica docente no processo ensino e aprendizagem na temática da inclusão social. 2015. 89f. Dissertação (Mestrado em Ensino, Ciências e Novas Tecnologias,) - Universidade Tecnológica Federal do Paraná, Londrina, 2015.

LIMA, Érika Rossana Passos de Oliveira; MOITA, Filomena $M^{a}$ Gonçalves da Silva Cordeiro. A tecnologia e o ensino de química: jogos digitais como interface metodológica. In: SOUSA, Robson Pequeno de; MOITA, Filomena M ${ }^{\mathrm{a}}$ G. da S. C.; CARVALHO, Ana Beatriz Gomes Carvalho. Tecnologias digitais na educação. Campina Grande: EDUEPB, 2011.

MARCONI, Marina de Andrade; LAKATOS, Eva Maria. Fundamentos de metodologia científica. 7. ed. São Paulo: Atlas, 2010.

PAULA, Francisco Leonardo de. Gamificação no ensino de língua portuguesa: proposta de atividades com gêneros jornalísticos e midiáticos. 2016. 105f. Dissertação (Mestrado Profissional em Letras) - Universidade do Estado do Rio Grande do Norte, Mossoró, 2016.

ROSETTI JR, Hélio. et al. O jogo na educação matemática: desenvolvimento de um rpg para trabalhar o conceito de moeda no ensino fundamental. HOLOS, Instituto Federal do Rio Grande do Norte (IFRN). v. 8, 2015, p. 113 - 121. ISSN: 1807-1600. Disponível em: <http://www2.ifrn.edu.br/ojs/index.php/HOLOS/article/view/3607> Acesso em: $16 / 11 / 2017$, às $20 \mathrm{~h}$.

SAVI, Rafael; ULBRICHT, Vania Ribas. Jogos digitais educacionais: benefícios e desafios. Renote - Revista Novas Tecnologias na Educação. Porto alegre, n. 2, v. 6, ISSN 1679-1916. 2008. Disponível em: <http://seer.ufrgs.br/index.php/renote/article/view/14405> Acesso em: 18/11/2017, às $21 \mathrm{~h}$.

SILVA, Leonardo Alves. et al. Uso dos jogos digitais em disciplinas científicas do nível superior: teorias e argumentos para sua implementação. In: XI ENPEC, 11., 2017, Santa Catarina. Anais... Florianópolis: UFSC, 2017, p. 01-11.

VIANNA, Ysmar. et al. Gamification, Inc: como reinventar empresas a partir de jogos. 1. ed. Rio de Janeiro: MJV Press, 2013. 